\title{
Acquisition of Pavlovian Fear Conditioning Using $\beta$-Adrenoceptor Activation of the Dorsal Premammillary Nucleus as an Unconditioned Stimulus to Mimic Live Predator-Threat Exposure
}

\author{
Eloisa Pavesi', Newton S Canteras' ${ }^{2}$ and Antônio P Carobrez ${ }^{*, 1}$ \\ 'Departamento de Farmacologia, CCB, Universidade Federal de Santa Catarina, Florianópolis, SC, Brazil; '2Departamento de Anatomia, ICB, \\ Universidade de São Paulo, São Paulo, SP, Brazil
}

\begin{abstract}
In the present work, we sought to mimic the internal state changes in response to a predator threat by pharmacologically stimulating the brain circuit involved in mediating predator fear responses, and explored whether this stimulation would be a valuable unconditioned stimulus (US) in an olfactory fear conditioning paradigm (OFC). The dorsal premammillary nucleus (PMd) is a key brain structure in the neural processing of anti-predatory defensive behavior and has also been shown to mediate the acquisition and expression of antipredatory contextual conditioning fear responses. Rats were conditioned by pairing the US, which was an intra-PMd microinjection of isoproterenol (ISO; $\beta$-adrenoceptor agonist), with amyl acetate odor - the conditioned stimulus (CS). ISO (I0 and 40 nmol) induced the acquisition of the OFC and the second-order association by activation of $\beta$-I receptors in the PMd. Furthermore, similar to what had been found for contextual conditioning to a predator threat, atenolol ( $\beta$ - I receptor antagonist) in the PMd also impaired the acquisition and expression of OFC promoted by ISO. Considering the strong glutamatergic projections from the PMd to the dorsal periaqueductal gray (dPAG), we tested how the glutamatergic blockade of the dPAG would interfere with the OFC induced by ISO. Accordingly, microinjections of NMDA receptor antagonist (AP5, $6 \mathrm{nmol}$ ) into the dPAG were able to block both the acquisition, and partially, the expression of the OFC. In conclusion, we have found that PMd $\beta$-I adrenergic stimulation is a good model to mimic predatory threat-induced internal state changes, and works as a US able to mobilize the same systems involved in the acquisition and expression of predator-related contextual conditioning.
\end{abstract}

Neuropsychopharmacology (201 I) 36, 926-939; doi:I0.1038/npp.2010.231; published online 5 January 201 I

Keywords: dorsal premammillary nucleus; $\beta$-adrenoceptor; $\beta$-adrenergic agonist; olfactory fear conditioning; defensive behavior; interoceptive stimulus

\section{INTRODUCTION}

The foundation to understand learning and memory processes lies on complex animal model paradigms, developed as a tool to obtain a temporal discrimination of acquisition, consolidation, reconsolidation or updating, and expression of new information (Bustos et al, 2009; Nader and Einarsson, 2010; Schafe et al, 2001). By exposing a subject to a sequential chain of aversive events, the fear conditioning model, derived from Pavlovian classical

* Correspondence: Dr AP Carobrez, Departamento de Farmacologia, Universidade Federal de Santa Catarina, Campus Trindade, 88040-900, Florianópolis, SC, Brazil, Tel: +55 483 721 4845; Fax: +55 483337 5479; E-mail: adepadua@farmaco.ufsc.br

Received 16 August 2010; revised 27 November 2010; accepted 29 November 2010 conditioning, is able to test frame-by-frame how subjects behave to cope with the various threatening situations.

Olfactory fear conditioning (OFC) has been increasingly used as a valuable tool to study fear-related systems. Memory for odors is often associated with highly emotional experiences, and recently, odors have been identified as one of the precipitants of trauma symptoms in posttraumatic stress disorder in war veterans (Vermetten et al, 2007). Furthermore, olfaction is the most important sensory system for rodents, and olfactory cues are critical to social interaction, anti-predatory defense, prey hunting, and feeding (Brennan and Keverne, 1997; Restrepo et al, 2004). This way, OFC has been used as a valuable tool to explore neural systems underlying fear responses and is considered an extremely consistent phenomenon, providing marked defensive behavior, such as freezing and potentiated startle responses (Kilpatrick and Cahill, 2003; Otto 
et al, 1997, 2000; Paschall and Davis, 2002a; Richardson et al, 1999).

In animal testing, the majority of fear conditioning studies has applied foot shocks as the aversive promoter event (Campeau et al, 1992; Davis, 1989; Delgado et al, 2008; Kroon and Carobrez, 2009; Schafe et al, 2005; Yap and Richardson, 2007). However, interventions able to modify the internal mood of the subject (eg thirst, hunger, and nausea-inducing drugs) could also be used as unconditioned stimulus (US) and bring new insights to understand the modulation of fear conditioning acquisition and its behavioral expression (Barnett, 1964; Lal and Emmett-Oglesby, 1983; Parker, 2006; Wood et al, 2007). We have recently found that the interoceptive changes induced by systemic administration of pentylenetetrazole (PTZ; non-competitive GABAa receptor antagonist) may work as an effective US in OFC, promoting a conditioned stimulus (CS)-US association strong enough to further induce a second-order CS to a contextual cue (Cavalli et al, 2009).

In the present work, we sought to mimic the internal state changes in response to a predator threat by pharmacologically stimulating the brain circuit involved in mediating predator fear responses, and explored whether this stimulation would be a valuable US in an OFC paradigm. A great deal of evidence suggests the medial hypothalamic defensive system, centered around the anterior hypothalamic nucleus, dorsomedial part of the ventromedial hypothalamic nucleus, and the dorsal premammillary nucleus (PMd), has a pivotal role in processing inputs from amygdalar circuits integrating predator-derived cues, and from the septohippocampal system relaying contextual processing from a predator-related environment (Canteras, 2002; Cezario et al, 2008; Martinez et al, 2010; Pentkowski et al, 2006). The PMd occupies a strategic position in the medial hypothalamic defensive system, and is one of the most responsive hypothalamic sites during exposure to a predator or its odor, and to a context previously associated with a predatory threat. Lesions centered therein severely reduced the defensive responses to both a live cat and its odor (Blanchard et al, 2003; Canteras et al, 1997; Cezario et al, 2008). In addition, pharmacological inactivation of the PMd, immediately before the exposure to a context previously associated with a predator or its odor, was able to practically abolish the contextual conditioned responses (Canteras et al, 2008; Cezario et al, 2008; Do Monte et al, 2008). Conversely, electric stimulation (Yardley and Hilton, 1986) or microinjections of GABA antagonist (Di Scala et al, 1984 ) in the PMd region induced a pattern of somatomotor and autonomic responses similar to the behavior of animals facing natural threats.

Anatomical and functional findings have proposed that descending projections from the PMd to the periaqueductal gray (PAG) are critical for the expression of unconditioned defensive reactions during exposure to a predator or its odor, as well as contextual conditioned responses to an environment previously associated with a predator threat (Cezario et al, 2008). In line with this view, the pattern of projection from the PMd to the PAG matches perfectly well the pattern of PAG Fos expression seen in response to a live predator or to a predator-associated context (Canteras and Goto, 1999; Canteras and Swanson, 1992; Cezario et al, 2008;
Motta et al, 2009). Therefore, it is plausible to suggest the activation of the PMd-PAG path as a suitable model to mimic the neural processing triggered by a real predatory threat.

Do Monte et al (2008) have shown that fear responses to predatory threats rely heavily on the PMd $\beta$-adrenergic neurotransmission. Thus, it has been shown that propranolol, injected systemically, significantly reduced PMd-Fos expression in response to cat odor, and that $\beta$-adrenoceptor blockade, in the PMd, reduced defensive responses to both cat odor exposure and cat odor-related context (Do Monte et al, 2008).

This way, we have presently tested whether the PMd $\beta$-adrenoceptors stimulation would work as an appropriate US in an OFC paradigm. The present results support the idea that the PMd $\beta$-adrenergic stimulation seem to induce marked internal state changes resembling in many ways those induced by predatory threat, and worked as a valuable US during OFC. Furthermore, we have presently investigated possible paths mediating such US-CS associations and have found an unexpected role for the PAG in the acquisition phase of OFC.

\section{MATERIALS AND METHODS}

\section{Subjects and Housing}

Adult male Wistar rats (12-15 weeks) weighing 300-400 g obtained from the University laboratory animal house were used in this study. The rats were kept in 3-4 subjects/cage $\left(50 \times 30 \times 15 \mathrm{~cm}^{3}\right)$, under controlled temperature $\left(22-24^{\circ} \mathrm{C}\right)$ and illumination ( $12 \mathrm{~h}$ cycle), and had free access to water and standard laboratory food. All experimental procedures and maintenance of the subjects had been previously approved by the Ethics Committee on Use of Laboratory Animals of the Federal University of Santa Catarina, Brazil (23080.008789/2009-46/UFSC).

\section{Stereotaxic Surgery}

Ten days before the beginning of the experiments, all subjects $(n=219)$ were submitted to a stereotaxic surgery for cannula implant into the PMd. The rats were anesthetized with a solution of ketamine $(15 \mathrm{mg} / \mathrm{kg}$, Cetamin; Syntec, Brazil) and xylazine $(2.5 \mathrm{mg} / \mathrm{kg}$, Xilazin; Syntec, Brazil) 3:2 v/v, $1 \mathrm{ml} / \mathrm{kg}$ body weight, and were positioned in a stereotaxic frame. Xylocaine $(0.1 \mathrm{ml}, 2 \mathrm{mg} /$ $\mathrm{ml}$; Probem, Brazil) was subcutaneously injected into the scalp and a longitudinal incision was made. Rats microinjected into the PMd received a stainless-steel guide cannula $(0.7 \mathrm{~mm}$ external diameter; $15 \mathrm{~mm}$ length) stereotaxically implanted, in a median position, with the cannula tip $3 \mathrm{~mm}$ above the PMd (coordinates from bregma: $\mathrm{AP}=4.16 \mathrm{~mm} ; \mathrm{ML}=0.8 \mathrm{~mm} ; \mathrm{DV}=6.5 \mathrm{~mm}$ from the skull surface at an angle of $10^{\circ}$ ). Note that the PMd has a very limited rostro-caudal extension, ranging around $400 \mu \mathrm{m}$. Rats microinjected into the PMd and the dorsolateral periaqueductal matter received a second cannula $(0.7 \mathrm{~mm}$ external diameter; $13 \mathrm{~mm}$ length) implant $3.2 \mathrm{~mm}$ above the dorsal periaqueductal gray (dPAG) (coordinates from bregma: $\mathrm{AP}=8.0 \mathrm{~mm} ; \mathrm{ML}=1.9 \mathrm{~mm} ; \mathrm{DV}=2.0 \mathrm{~mm}$ from the skull surface at an angle of $21^{\circ}$ ). 
The cannulas were fixed with polyacrylic cement and anchored to the skull with stainless-steel screws. At the end of the surgery, each guide cannula was sealed with a stainless-steel wire to protect it from obstruction. In addition, the subjects received an intramuscular injection of Pentabiotic (60000 IU, $0.2 \mathrm{ml}$; Fort Dodge, Brazil) and a subcutaneous injection $(10 \mathrm{mg} / \mathrm{ml})$ of the anti-inflammatory and analgesic Banamine (flunixinmeglumine, $2.5 \mathrm{mg} / \mathrm{kg}$; Schering-Plough, Brazil).

\section{Drugs and Microinfusion Procedure}

Isoproterenol (ISO) ((DL)1-3'4'dihydroxyphenyl-2-isopropyl aminoethanol; Sigma, USA), atenolol ((RS)-Atenolol; Tocris, USA), butoxamine (butoxamine hydrochloride; Sigma, USA) were dissolved in phosphate-buffered saline (PBS), which alone was used as a vehicle control of microinjection into the PMd. (DL)-2-amino-5-phosphonopentanoic acid (AP5; RBI, USA) were dissolved in 0.1 M PBS $(\mathrm{pH}=7.4)$, which alone served as vehicle control of microinjection into the dPAG. Drug dosage, volume $(0.3 \mu \mathrm{l}$ for PMd and $0.2 \mu \mathrm{l}$ for dPAG) and rate of infusion $(0.6 \mu \mathrm{l} /$ min) were chosen based on previous studies (Do Monte et al, 2008; Kincheski and Carobrez, 2010; Qu et al, 2008; Watanabe et al, 2003).

For intracerebral drug administration, subjects were gently held, the stainless-steel wire was removed and a stainless-steel needle (18 mm long for PMd; $16.2 \mathrm{~mm}$ long for dPAG; $0.35 \mathrm{~mm}$ external diameter) was inserted into the guide cannula. The needle was connected to a $5-\mu$ Hamilton syringe through polyethylene (PE-10) tubing attached to an infusion pump (B12000 model; Insight, Brazil).

\section{Apparatuses and Experimental Procedures}

This study was realized in two different apparatus: a conditioning box and an odor box, described by Kroon and Carobrez (2009), during 5 consecutive days. The first 2 days were conducted in the conditioning box for the acquisition of OFC. The remaining 3 days were performed in the odor box to verify the fear conditioning expression.

The conditioning apparatus $\left(50 \times 26 \times 35 \mathrm{~cm}^{3}\right)$ was constructed with stainless-steel walls and a grid floor composed of $1 \mathrm{~cm}$ spaced stainless-steel bars (Insight, Brazil). The conditioning box was housed in a sound-attenuating room with illumination level of 80 lux.

The odor chamber was used to measure the behavior exhibited to the CS, in a low illumination room (4lux). The odor box was made up of black Plexiglas and consisted of two compartments, an open compartment $\left(40 \times 26 \times 40 \mathrm{~cm}^{3}\right)$ and an enclosed (roofed) compartment $\left(20 \times 26 \times 40 \mathrm{~cm}^{3}\right)$. A $6 \times 6 \mathrm{~cm}^{2}$ open door allowed the rat to move through both compartments. On the opposite wall of the enclosed compartment, a cloth containing $(250 \mu \mathrm{l})$ amyl acetate odor (Amyl acetate $99+\%$ SAFC Supply Solutions; St Louis, MO, USA) was used as the CS. The choice of amyl acetate odor at a 5\% dilution as a CS was based on previous studies (Kilpatrick and Cahill, 2003; Paschall and Davis, 2002a). The frontal side of the chamber was made up of clear Plexiglas allowing a video camera and corresponding DVD system to record the animals' behavior. After each session, and between subjects, the apparatuses were cleaned with a10\% alcohol-water solution.
The behavioral analyses were scored in the odor box, by an observer without previous knowledge of the animal's experimental status. The time spent near $(7 \mathrm{~cm})$ the odor source (approach time), the time spent in the enclosed compartment (hide time), and the time performing stretching-out postures from the enclosed compartment towards the open compartment (head-out time) were used to calculate the respective percentage relative to the session time (10 min).

\section{Experimental Groups}

Experiment 1 -effects of ISO in the acquisition of OFC. After 10 days have elapsed, the subjects were placed in the conditioning box, during $3 \mathrm{~min}$ and $20 \mathrm{~s}$, for a familiarization period (day 1 ). After $24 \mathrm{~h}$, they were randomly divided in four experimental groups: (1) PBS + CS; (2) ISO $10 \mathrm{nmol}$ + CS; (3) ISO $40 \mathrm{nmol}+\mathrm{CS}$; and (4) ISO $40 \mathrm{nmol}$-no odor. Five minutes after the treatment, except for the ISO-no odor group, the rats were placed in the conditioning box, containing $250 \mu \mathrm{l}$ of amyl acetate solution absorbed in a $10 \times 10 \mathrm{~cm}^{2}$ filter paper. The rats remained in the conditioning box during $10 \mathrm{~min}$.

The expression of OFC was performed in the odor box and consisted of three consecutive sessions (10 min duration), spaced $24 \mathrm{~h}$ apart. In the familiarization session (day 3), the subjects were habituated to the novel apparatus and baseline levels of behavioral parameters were measured in the absence of the CS. On the following day, behavioral parameters of fear expression were measured in the subjects confronted with the CS (CS1). After $24 \mathrm{~h}$, the rats were placed in the same context without the amyl acetate odor. This later session allowed determination of second-order conditioning (CS2) occurring as the result of pairing between conditioned odor (CS1) and the context where the CS had been presented. During both the familiarization and the CS2 session, a neutral odor cloth was used only as a visual cue.

Experiment 2-atenolol and butoxamine effects on the acquisition of OFC induced by ISO. To identify the subtype of receptor involved in this drug effects, the subjects received atenolol ( $\beta-1$ antagonist) or butoxamine $(\beta-2$ antagonist) $5 \mathrm{~min}$ prior to ISO microinjection. Subjects received PBS, atenolol $(40 \mathrm{nmol})$, or butoxamine $(10 \mathrm{nmol})$ followed by ISO $(40 \mathrm{nmol})$, and were placed in the conditioning odor with the presence of amyl acetate odor during $10 \mathrm{~min}$. Two groups of rats were microinjected with atenolol $(40 \mathrm{nmol})$ or butoxamine $(10 \mathrm{nmol})$ followed by PBS. Subjects receiving two separated microinjections of PBS spaced $5 \mathrm{~min}$ and exposed to amyl acetate odor served as the control group.

All groups were further analyzed in 3 consecutive days in the odor box, during $10 \mathrm{~min}$ each session according to previous protocol.

Experiment 3-atenolol effects on the expression of OFC induced by ISO. All subjects were paired with ISO $40 \mathrm{nmol}$ in the PMd and CS during $10 \mathrm{~min}$. Ten minutes before the CS1 test session, the subjects were microinjected with PBS or atenolol $40 \mathrm{nmol}$ into the PMd. Subjects receiving PBS in the conditioning session and PBS before the CS1 test session 
served as the control group. The defensive behavior expression in the odor box was scored as previously described.

Experiment 4-dPAG-NMDA receptor antagonism effects on the acquisition and expression of the OFC induced by ISO. To verify the ability of ISO infusion in the PMd to induce fear conditioning acquisition through a descending glutamatergic pathway to the $\mathrm{APAG}$, subjects receiving two intracerebral cannulas aiming at the $\mathrm{dPAG}$ and the PMd were randomly assigned to one of the three groups: (1) PBS(dPAG) + PBS(PMd); (2) PBS + ISO $40 \mathrm{nmol}$; and (3) AP5 $6 \mathrm{nmol}+$ ISO $40 \mathrm{nmol}$. In all groups, the dPAG microinjection was performed $5 \mathrm{~min}$ before the PMd injection. Five minutes after the last treatment, the subjects were placed in the conditioning box containing amyl acetate odor during $10 \mathrm{~min}$. The defensive behavior expression was analyzed and scored as previously described.

To verify the ability of ISO infusion in the PMd to induce OFC expression through a descending glutamatergic pathway to the $\mathrm{dPAG}$, subjects receiving two intracerebral cannulas aiming at the dPAG and the PMd were randomly assigned to one of the three groups: (1) PBS(PMd)+ PBS(dPAG), (2) ISO $40 \mathrm{nmol}+\mathrm{PBS}$, and (3) ISO $40 \mathrm{nmol}+$ AP5 $6 \mathrm{nmol}$. Subjects of all groups were conditioned under PBS or ISO influence in the conditioning box. Ten minutes before CS1 test, in the odor box, the rats received either PBS or AP5 within the dPAG. The defensive behavior expression during familiarization, CS1 and CS2 was scored as previously described.

\section{Histological Analysis}

To evaluate the injection site placement, rats were deeply anesthetized with sodium pentobarbital $(40 \mathrm{mg} / \mathrm{kg}$; Cristália, Brazil) and were perfused transcardially with saline $(0.9 \% \mathrm{NaCl})$ and formaldehyde $(10 \%)$ for $10 \mathrm{~min}$ each. A volume of $0.3 \mu \mathrm{l}$ (PMd) or $0.2 \mu \mathrm{l}$ (dPAG) of Evans blue dye $(0.5 \%)$ was then administered through the same needle previously used in the experiments. After decapitation, the brain was removed from the skull and stored in formaldehyde $(10 \%)$ overnight. The brains were immersed in a sucrose solution $(30 \%)$ for cryoprotection. Coronal slices $(50 \mu \mathrm{m})$ were cut on a cryostat (Leica CM1850) and mounted on gelatin-coated slides. The sections were examined in an optical microscope to determine the injection sites delimited by the Evans blue dye.

Histological analysis confirmed that a total of 202 rats had accurate cannula placements in the PMd, while 51 rats had accurate cannula placements both in the PMd and dPAG. The PMd and dPAG schematic injection site plottings, as well as representative photomicrographs showing the PMd and APAG cannula placements are depicted in Figure 1. In the rats receiving ISO outside the $\mathrm{PMd}$, the microinjection hit the medial mammillary nucleus, caudal to the region of the PMd, and these rats were included in the ISO-out group $(n=17)$. The rats that had received AP5 in the superior colliculus, above the dPAG, were included in the dPAG-out group $(n=19)$.

\section{Statistics}

Treatment effects were analyzed by repeated measures (CS1 and CS2 trials) ANOVA. The approach time, the hide time, and the head-out time during the 10-min session were scored minute-by-minute, and the $10-\mathrm{min}$ collapsed data were transformed as the percentage of each measurement and used as dependent variables. When appropriate, pairwise comparisons using the Newman-Keuls' test were performed. The minimum level of statistical significance adopted was $p<0.05$. For graphics representations, the magnitude of $p$-values was divided into three levels: ${ }^{*} p<0.05,{ }^{* *} p<0.005$, and ${ }^{* * *} p<0.005$. All statistical analyses were performed using the Statistica software package (Version 9.1; StatSoft; Tulsa, USA).

\section{RESULTS}

\section{Effects of ISO in the Acquisition of OFC}

No statistical differences among the groups were detected by ANOVA in the behavioral parameters evaluated during familiarization phase. On the CS1 and CS2 test, ANOVA showed a significant treatment effect in the defensive behavior, represented by the \%approach time $(\mathrm{F}(4,46)=$ 25.43; $p<0.00001)$, \%hide-hide time $(\mathrm{F}(4,46)=45.12$; $p<0.00001)$, and \%head-out $(\mathrm{F}(4,46)=20.50 ; p<0.00001)$. Newman-Keuls' post hoc comparisons revealed a significant decreased \%approach time $(p<0.0005)$, and increased \%hide time $(p<0.0005)$ and \%head-out time $(p<0.0005)$ during CS1 test and CS2 test in the subjects that were microinjected with ISO $10(n=9)$ or $40 \mathrm{nmol}(n=11)$ who were conditioned to amyl acetate odor during $10 \mathrm{~min}$ when compared with PBS group $(n=7)$. No statistical difference was detected in the parameters observed in groups from ISO $40 /$ no odor $(n=7)$ compared with PBS group. Furthermore, no statistical difference was detected between subjects receiving ISO 10 or $40 \mathrm{nmol}$ outside from $\mathrm{PMd}$, and these rats were grouped in the ISO-out group $(n=17)$. The ISOout group showed no statistical difference compared with the control group in the parameters analyzed (Figure 2).

These results suggest that the ISO into the PMd could be used as US capable to support fear conditioning and second-order conditioning.

\section{Atenolol and Butoxamine Effects on the Acquisition of OFC Induced by ISO}

ISO is a non-specific $\beta$-adrenergic agonist, and to identify the subtype of receptor involved in this drug effects, the rats received atenolol ( $\beta-1$ receptor antagonist) $40 \mathrm{nmol}(n=8)$ or butoxamine $(\beta-2$ receptor antagonist) $10 \mathrm{nmol}(n=8)$ prior to ISO $40 \mathrm{nmol}$ microinjection. No statistical difference was detected by ANOVA among the groups for the behavior parameters observed in the apparatus during the familiarization day. ANOVA detected significant treatment effect for the \%approach time $(\mathrm{F}(5,44)=11.89 ; p<0.00001)$, \%hide time $(\mathrm{F}(5,44)=31.45 ; p<0.00001)$, and in the $\%$ head-out time $(\mathrm{F}(5,44)=13.35 ; p<0.00001)$. In addition, a trial effect was detected for the \%approach time $(\mathrm{F}(1,44)=5.99 ; \quad p<0.05), \quad \%$ hide time $(\mathrm{F}(1,44)=5.51$; $p<0.05)$, and in the \%head-out time $(\mathrm{F}(1,44)=6.50$; 

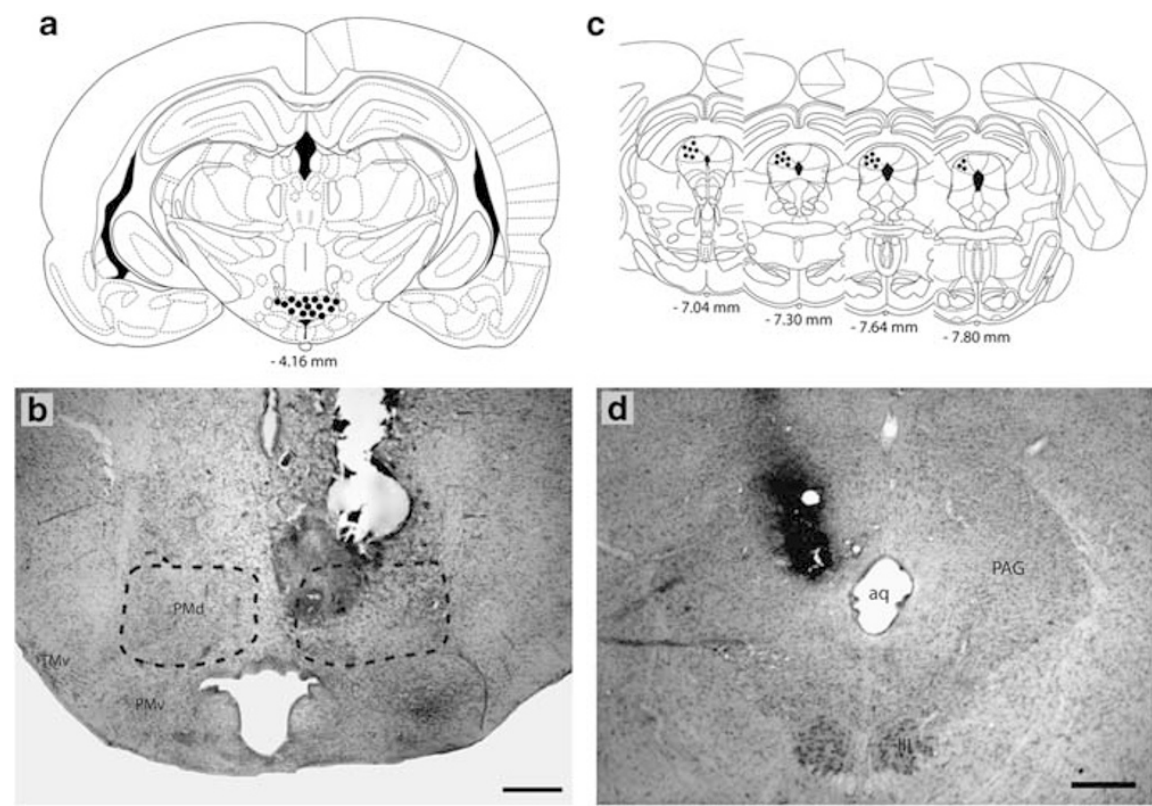

Figure I Schematic plotting onto a standard drawing of the rat brain (Paxinos and Watson, 1998) showing the approximate location of the injection cannula tips centered in the PMd region (a) and the dPAG (c). Due to the large number of overlaps, the number of plotted points is lower than the number of subjects actually injected in this region. (b) Bright-field photomicrograph of Evans blue-stained section showing the injection cannula placement in a representative animal that received isoproterenol into the PMd region. (d) Photomicrograph of Evans blue-stained section showing the injection cannula placement in a representative animal that received AP5 into the dPAG region. PMd, dorsal premammillary nucleus; PMv, ventral premammillary nucleus; PAG, periaqueductal gray; Aq, cerebral aqueduct; TMv, tuberomammillary nucleus, ventral part. Scale bar $=500 \mu \mathrm{m}$.

$p<0.05)$. Newman-Keuls' post hoc analyses showed a decreased $(p<0.05)$ \%approach time during CS1 and CS2 test for subjects from PBS + ISO $(n=11)$ and butoxamine + ISO groups when compared with control PBS + PBS group $(n=9)$. The \%hide time $(p<0.0005)$ and \%head-out $(p<0.05)$ time were increased in the PBS+ISO and butoxamine + ISO groups during CS1 and CS2 test compared with PBS + PBS (Figure 3). No statistical difference was detected from atenolol + ISO, atenolol + PBS $(n=6)$, and butoxamine + PBS $(n=8)$ groups compared with the control group.

Together, these results corroborate the establishment of an OFC by ISO- odor pairing, and indicate that atenolol, but not butoxamine, was able to impair ISO-associated conditioning.

\section{Atenolol Effects on the Expression of OFC Induced by ISO}

This experiment was conducted to verify the role of $\beta$-adrenoceptors in the PMd during the expression of the defensive responses to conditioned odor. No statistical difference was detected by ANOVA among the groups for the behavior parameters observed in the apparatus during the familiarization day. A significant treatment effect was detected on CS1 and CS2 test session for the \%approach time $(\mathrm{F}(3,26)=19.51 ; p<0.00001)$, \%hide time $(\mathrm{F}(3,26)=43.51 ; p<0.00001)$, and \%head-out time $(\mathrm{F}(3,26)=30.89 ; p<0.00001)$. In addition, a trial effect $(p<0.05)$ was detected for the \%approach time $(\mathrm{F}(1,26)=5.41)$. The post hoc Newman-Keuls' test revealed significant decreased \%approach time $(p<0.005)$ and increased \%hide time $(p<0.0005)$ and \%head-out time $(p<0005)$ in the CS1 and CS2 test session for the group receiving ISO $40 \mathrm{nmol}$ the conditioning day and PBS before CS1 test (ISO/PBS group, $n=9$ ), when compared with PBS + PBS control group $(n=8)$ (Figure 4$)$. The subjects that received atenolol $40 \mathrm{nmol}$ before CS1 test session (ISO/ATE, $n=8$ or PBS/ATE, $n=8$ groups) no statistical difference was detected compared with control group.

These results demonstrate that atenolol in the PMd is able to impair the expression of the OFC promoted by $\beta$-adrenoceptors stimulation in the PMd.

\section{Dorsolateral Periaqueductal Gray NMDA Receptors Antagonism Interference with the OFC Acquisition Induced by ISO and Expression of OFC}

In the following two sets of experiments, the hypothesis that a glutamatergic pathway arising from the PMd to $\mathrm{dPAG}$ could underlie the aversive state generated in the PMd was tested.

In the first set of results (Figure 5), none of the groups exhibited fear responses to the odor box during the familiarization session. Statistical treatment effects were detected by ANOVA for the \%approach time, $(\mathrm{F}(3,34)=17.94 ; p<0.00001), \%$ hide time $(\mathrm{F}(3,34)=32.40$; $p<0.00001), \quad$ and $\%$ head-out time $\quad(\mathrm{F}(3,34)=21.89$; $p<0.00001)$. Newman-Keuls' post hoc test revealed a significant reduced \%approach time $(p<0.005)$ and an increased \%hide time $(p<0.0005)$ and \%head-out time $(p<0.0005)$ in CS1 session for the subjects microinjected with PBS in the dPAG followed by ISO $40 \mathrm{nmol}$ in the PMd (PBS/ISO group, $n=10$ ) or subjects injected with AP5 $6 \mathrm{nmol}$ outside dPAG (AP5-out/ISO group, $n=10$ ) during the conditioning session. A remarkable blockade due to AP5 

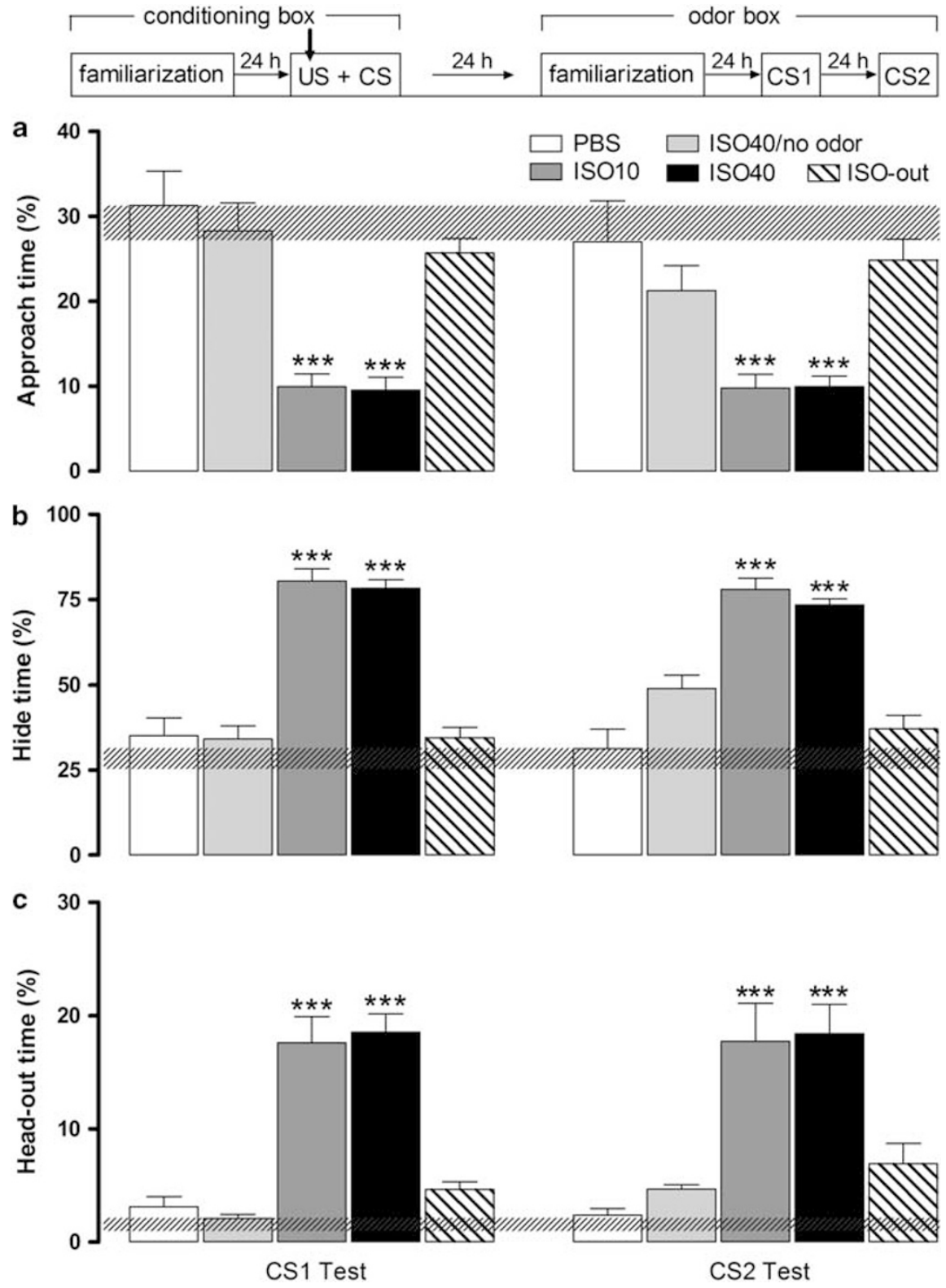

Figure 2 Isoproterenol (ISO) infusion in the PMd (US) promotes olfactory fear conditioning. The experimental design used is outlined above the graph where vertical arrow shows the moment of ISO microinjection. Histograms represent the mean (+ SEM) of the percentage of approach time (a), of hide time (b), and of head-out time (c). The hatched horizontal bars represent the mean and the confidence limits (within 95\%) for the familiarization session in the odor box. PBS $(n=7)$, ISO I $0 \mathrm{nmol}(n=9)$, and ISO $40 \mathrm{nmol}(n=1 \mathrm{I})$ in the PMd and ISO-out $(n=17)$ group were conditioned to amyl acetate odor (CS). Subjects from ISO $40 \mathrm{nmol} / \mathrm{no}$ odor $(n=7)$ were not exposed to CS during conditioning session. CSI represents the first-order CS exposure and CS2 represents the second-order context (no odor) exposure. **** $p 0.0005$ compared with the PBS control group (repeated measures ANOVA followed by Newman-Keuls' test).

$6 \mathrm{nmol}$ infusion into dPAG was responsible for the lack of statistical difference in the ISO-conditioning (AP5/ISO) group $(n=11)$ not being different from PBS/PBS group $(n=7)$. During CS2 session, subjects from PBS/ISO group continued to show a decreased \%approach time $(p<0.005)$ and an increased \%hide time $(p<0.0005)$ and \%head-out time $(p<0.0005)$ compared with the control group. Subjects from AP5-out/ISO group showed an increased \%hide time $(p<0.005)$ and \%head-out $(p<0.005)$ time compared with control group. No statistical difference was detected during CS2 session between AP5/ISO group compared with the control group in the parameters observed (Figure 5).
In the second set of results (Figure 6), none of the groups exhibited fear responses to the odor box during the familiarization session. Statistical treatment effects were detected by ANOVA for the \%approach time $(\mathrm{F}(3,28)=$ 6.13; $p<0.01)$, \%hide time $(\mathrm{F}(3,28)=17.06 ; p<0.01)$, and in the \%head-out time $(\mathrm{F}(3,28)=13.47 ; p<0.01)$. In addition, an interaction between trial $\mathrm{X}$ treatment effect was detected for the \%approach time $(\mathrm{F}(3,28)=6.05 ; p<0.05)$ and \%hide time $(\mathrm{F}(3,28)=4.81 ; p<0.05)$. Post hoc Newman-Keuls' comparisons revealed, during CS1 session, a significant reduced \%approach time $(p<0.005)$ and an increased $\%$ hide time $(p<0.0005)$ and \%head-out time $(p<0.0005)$ 

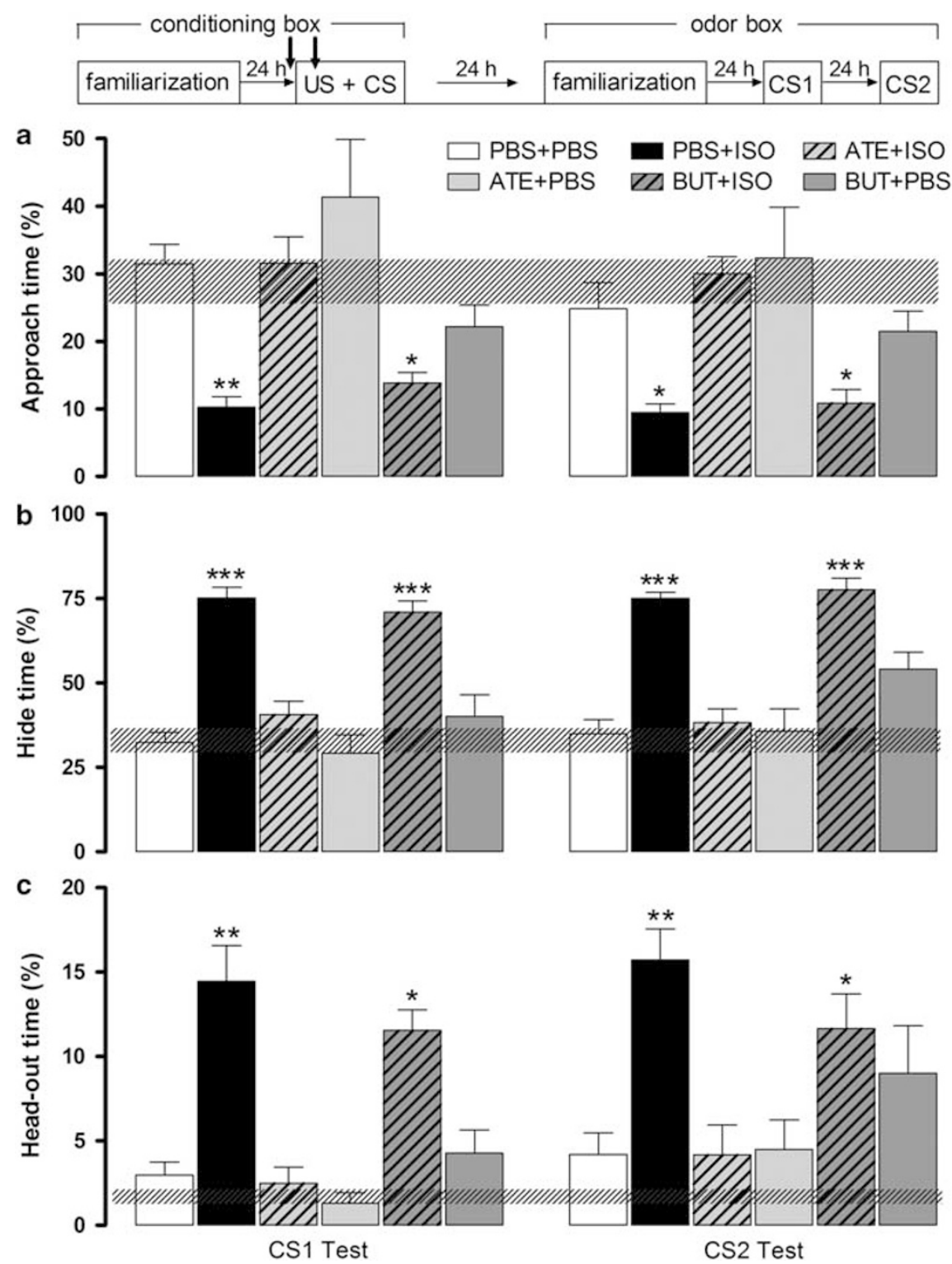

Figure 3 Atenolol (ATE) but not butoxamine (BUT) impairs the acquisition of olfactory fear conditioning promoted by isoproterenol (ISO) infusion in the PMd. The experimental design used is outlined above the graph where vertical arrows show the moment of ATE or BUT, and ISO microinjection (5 min apart), respectively. Histograms represent the mean (+ SEM) of the percentage of approach time (a), of hide time (b), and of head-out time (c). The hatched horizontal bars represent the mean and the confidence limits (within 95\%) for the familiarization session in the odor box. PBS + PBS ( $n=9)$, PBS + ISO $40 \mathrm{nmol}(n=1 \mathrm{I})$, ATE $40 \mathrm{nmol}+\mathrm{ISO} 40 \mathrm{nmol}(n=8)$, ATE $40 \mathrm{nmol}+\operatorname{PBS}(n=6)$, BUT I $0 \mathrm{nmol}+1 \mathrm{SO} 40 \mathrm{nmol}(n=8)$, or BUT I0 nmol + PBS $(n=8)$ group were conditioned to amyl acetate odor (CS). CSI represents the first-order CS exposure and CS2 represents the second-order context (no odor) exposure. $* p<0.05$, ** $p<0.005$, **** $<0.0005$ compared with the PBS + PBS control group (repeated measures ANOVA followed by Newman-Keuls' test).

in subjects that received ISO $40 \mathrm{nmol}$ into the PMd in the conditioning session and PBS into the dPAG before CS1 (ISO/PBS group, $n=9$ ) and in the subjects that received ISO in the PMd and AP5 $6 \mathrm{nmol}$ outside dPAG (ISO/AP5-out group, $n=9$ ). Subjects that were microinjected with ISO $40 \mathrm{nmol}$ in the PMd and AP5 $6 \mathrm{nmol}$ in the dPAG (ISO/AP5, $n=7)$ showed decreased $(p<0.05)$ \%approach time during CS1 session compared with control group (PBS/PBS, $n=7$ ). A blockade due to AP5 infusion into dPAG before CS1 session was responsible for the lack of statistical difference in the expression of ISO-conditioning group in \%hide and \%head-out times. During CS2 session, the subjects from ISO/PBS and ISO/AP5-out groups continued to show an increased \%hide time $(p<0.05)$ compared with control group. No statistical difference was detected during CS2 session between ISO/AP5 group compared with control group in the parameters observed (Figure 6).

Together, these findings indicate that blockade of NMDA receptors in the PAG impair the effective ISO-CS association, and therefore, the acquisition of OFC. On the other hand, the OFC expression was only partially reduced by AP5 microinjection before the CS1 test. 

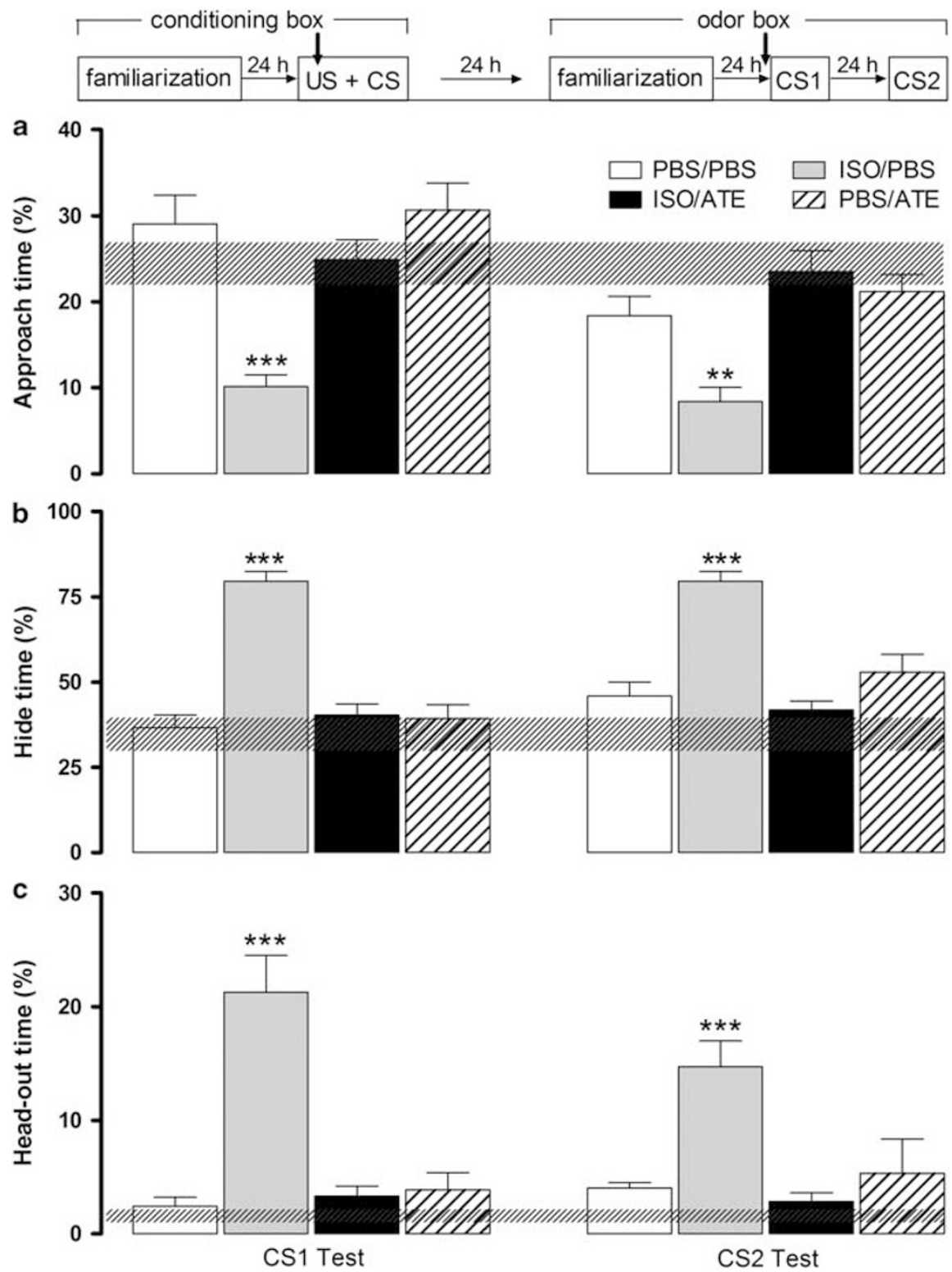

Figure 4 Atenolol (ATE) impairs the expression of olfactory fear conditioning (OFC) promoted by isoproterenol (ISO) infusion in the PMd. The experimental design used is outlined above the graph where vertical arrows show the moment of ISO and ATE microinjection, respectively. Histograms represent the mean ( + SEM) of the percentage of approach time (a), of hide time (b), and of head-out time (c). The hatched horizontal bars represent the mean and the confidence limits (within 95\%) for the familiarization session in the odor box. PBS/PBS $(n=8)$, ISO $40 \mathrm{nmol} / \mathrm{PBS}(n=9)$, ISO $40 \mathrm{nmol} / \mathrm{ATE}$ $40 \mathrm{nmol}(n=8)$, and PBS/ATE $40 \mathrm{nmol}(n=8)$ group were conditioned to amyl acetate odor $(C S)$ and received the second injection before OFC expression. CSI represents the first-order CS exposure and CS2 represents the second-order context (no odor) exposure. $* *$ $p<0.005$, $* * * *<<0.0005$ compared with the PBS/PBS control group (repeated measures ANOVA followed by Newman-Keuls' test).

\section{DISCUSSION}

The results obtained in this study tested whether $\beta$ adrenoceptors stimulation in the PMd would result in internal state changes strong enough to support olfactory conditioning of fear nature. The olfactory system in rodents is important for several functions, such as recognition and discrimination among individuals of their own species, reproduction, parental behavior, feeding, and recognition of predator (Brennan et al, 1997; Restrepo et al, 2004; Sam et al, 2001). We have presently used the OFC task described by Kroon and Carobrez (2009), in which one box was used for olfactory conditioning acquisition (the conditioning box), and another one for the OFC expression (the odor box). In this protocol, after conditioning, rats were initially submitted to the odor box in a familiarization session to test for possible generalization. Fearless behavioral baseline responses to a neutral odor indicate no generalization, and assure the isolation of the olfactory cue from the context, as the only aversive source for conditioning. The efficacy of the OFC was analyzed and scored from subtle defensive behavioral displays, such as the time spent near the CS, the time spent in the enclosed compartment and the time spent heading out, engaging in risk assessment behavior. According to previous studies (Canteras et al, 2008; Kroon and Carobrez, 2009), this paradigm renders it possible to 

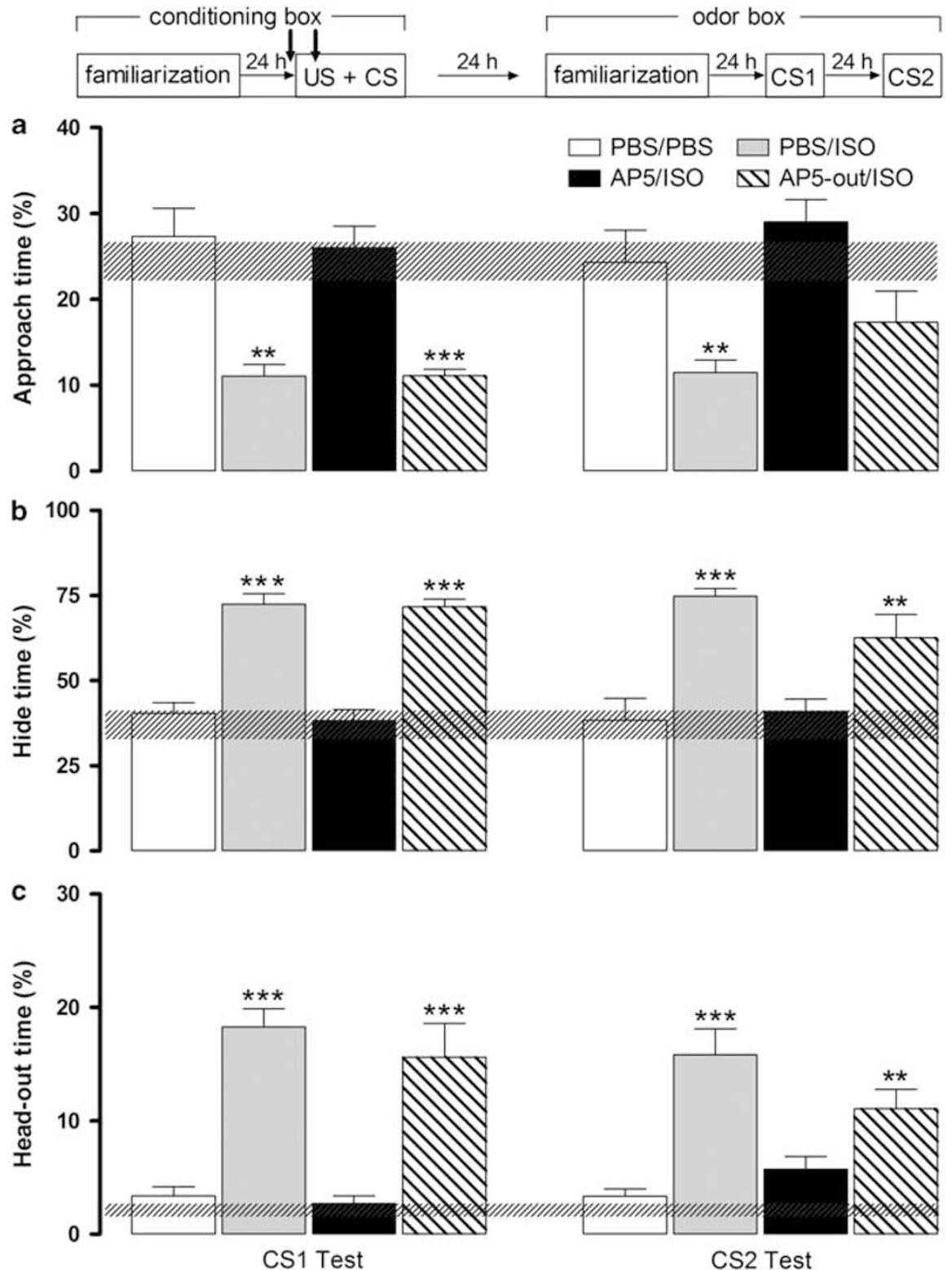

Figure 5 DL-2-amino-phosphonovaleric acid (AP5) in the dPAG impairs the acquisition of olfactory fear conditioning promoted by isoproterenol (ISO) infusion in the PMd. The experimental design used is outlined above the graph where vertical arrows show the moment of AP5 (6 nmol) microinjection in the APAG and ISO (40 nmol) infusion in the PMd (5 min apart), respectively. Histograms represent the mean ( + SEM) of the percentage of approach time (a), of hide time (b), and of head-out time (c). The hatched horizontal bars represent the mean and the confidence limits (within 95\%) for the familiarization session in the odor box. PBS/PBS $(n=7)$, PBS/ISO $(n=10)$, or AP5/ISO $(n=11)$ and AP5-out/ISO $(n=10)$ groups were conditioned to amyl acetate odor (CS). CSI represents the first-order CS exposure and CS2 represents the second-order context (no odor) exposure. ** $p<0.005$, **** $p<0.0005$, compared with the PBS/PBS control group (repeated measures ANOVA followed by Newman-Keuls' test).

interfere with the rate and level of OFC acquisition, and by isolating the olfactory stimulus as the only threaten cue in the odor box, it allows to control the expression level of fear conditioning responses. In this model, in addition to testing the US-CS association strength by measuring, in the odor box, the level of defensive responses to the first-order conditioning stimulus (CS1), it also allows to examine the CS1 further promoting a contextual second-order conditioning (CS2), as the result of CS1-context pairing (Kroon and Carobrez, 2009; Cavalli et al, 2009). This OFC model has been shown to be sensitive to different classes of compounds, such as benzodiazepines, $\beta$-adrenoceptor blockers and anti-colinergic drugs (Kroon and Carobrez, 2009). Moreover, it also supports the use of alternative USs that produce marked internal state changes, such as the systemic application of the PTZ (Cavalli et al, 2009).

Instead of using mild aversive stimuli, such as electrical foot shock, the use of alternative unconditioned stimuli able to modify the internal physiological state or mood of the subject should provide a broader understanding on how fear conditioning mechanisms work under more natural conditions. In the present study, we attempted to induce a predator-threat-related internal mood change by stimulating $\beta$-adrenoceptors in the PMd, which was used as the US 

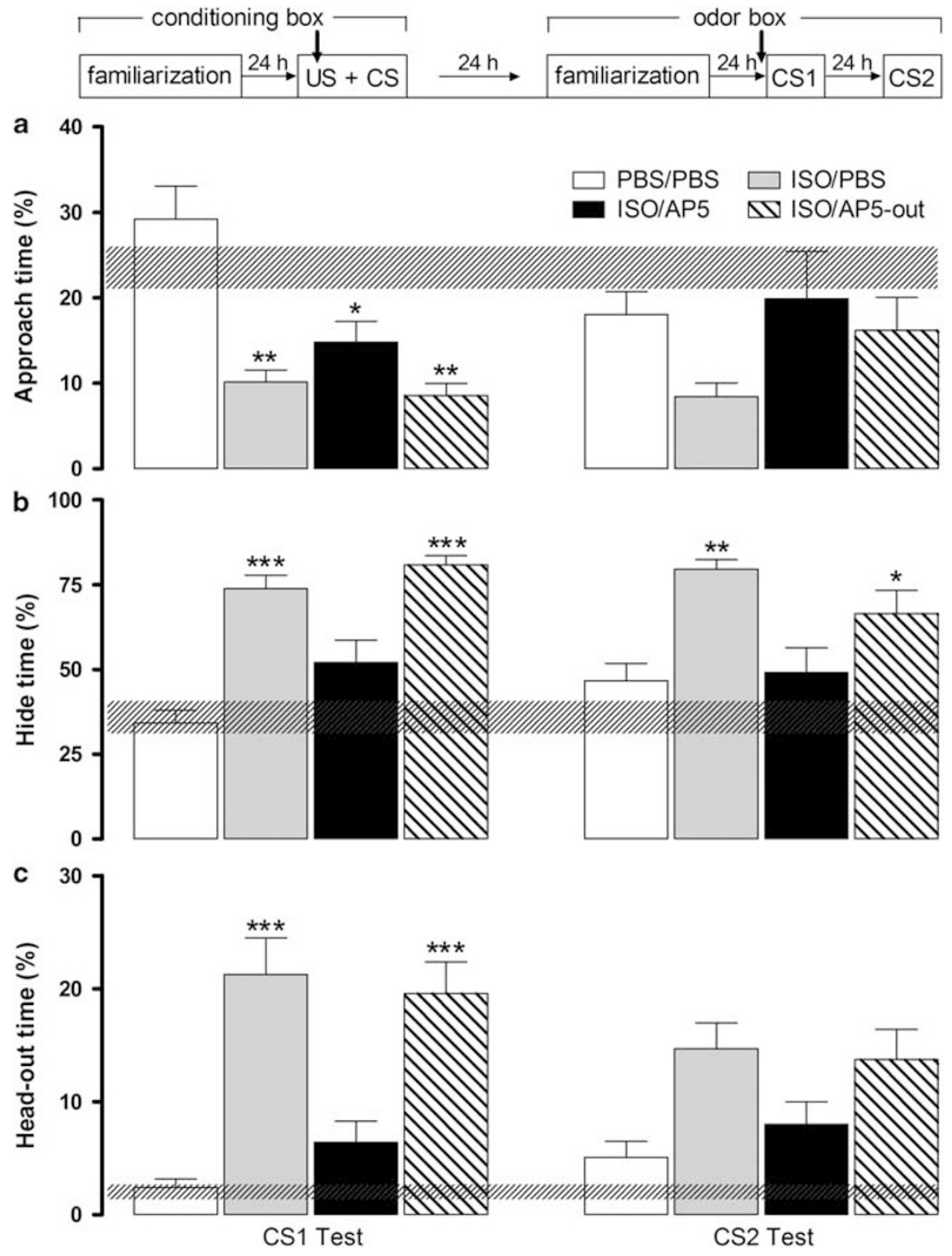

Figure 6 DL-2-amino-phosphonovaleric acid (AP5) in the APAG impairs the expression of olfactory fear conditioning promoted by isoproterenol (ISO) infusion in the PMd. The experimental design used is outlined above the graph where vertical arrows show the moment of ISO (40 nmol) infusion in the PMd and of AP5 $(6 \mathrm{nmol})$ microinjection in the dPAG, respectively. Histograms represent the mean ( + SEM) of the percentage of approach time (a), of hide time (b), and of head-out time (c). The hatched horizontal bars represent the mean and the confidence limits (within 95\%) for the familiarization session in the odor box. PBS/PBS $(n=7)$, ISO/PBS $(n=9)$, ISO/AP5 $(n=7)$, and ISO/AP5-out $(n=9)$ groups were conditioned to amyl acetate odor (CS). CSI represents the first-order CS exposure and CS2 represents the second-order context (no odor) exposure. $* p<0.05$, $* * p<0.005$, **** $p<0.0005$, compared with the PBS/PBS control group (repeated measures ANOVA followed by Newman-Keuls' test).

in our OFC model. Accordingly, the subjects that received ISO in the PMd associated with amyl acetate odor as CS showed, $48 \mathrm{~h}$ after the conditioning, a marked defensive behavior towards the amyl acetate odor alone. Neither animals injected with PBS, nor those infused with ISO outside the PMd were able to express emotional responses towards the CS. Importantly, none of the groups exhibited defensive behavior during the familiarization session in the odor box, suggesting that the subjects did not show generalized fear to stimuli other than the amyl acetate odor. Furthermore, the first-order conditioning stimulus (CS1)-context pairing was able to induce a second-order association, demonstrated during the second-order con- ditioning (CS2) test, where the level of defensive responses exhibited were similar to those observed during the CS1 test session. Thus, the re-exposure to the CS in a new context (the CS1 test session) was able to promote a new association between the CS1 and the context (CS2), where it was re-exposed, resulting in a second-order fear conditioning. It is important to mention that olfactory cues have been shown to serve as efficient stimuli in second-order fearpotentiated startle paradigms (Paschall and Davis, 2002b).

ISO is a non-selective $\beta$-adrenergic agonist, and we have performed further pharmacological analyses using selective $\beta-1$ (atenolol) or $\beta-2$ (butoxamine) antagonists microinjected into the PMd. Subjects pretreated with atenolol failed 
to exhibit the ISO-OFC acquisition, while those pretreated with butoxamine showed marked defensive responses. Moreover, atenolol microinjected into the $\mathrm{PMd}$, immediately previous to the first-order conditioning stimulus (CS1), also blocked the contextual second-order conditioning. Therefore, stimulation of PMd $\beta-1$ adrenoceptors should be involved in mediating both ISO-OFC acquisition and second-order contextual conditioning. In line with this view, atenolol microinjected into the PMd also blocked contextual conditioning to a cat odor-associated environment (Do Monte et al, 2008). Based on the results obtained with the presently used dose of butoxamine, we cannot rule out a possible $\beta-2$ effects on the OFC acquisition. Butoxamine has been shown to decrease auditory fear conditioning consolidation after a $0.5-\mu \mathrm{l}$ amygdalar injection, at the dose of $30 \mathrm{nmol}$ ( $\mathrm{Qu}$ et al, 2008). However, due to the small PMd dimensions, we had to use smaller injection volumes $(0.3 \mu \mathrm{l})$ implicating in higher concentration and insolubility in PBS.

Moreover, atenolol microinjected into the PMd, immediately previous to the first-order conditioning stimulus (CS1), also blocked the fear conditioning expression in ISO-OFC rats, indicating that the expression of defensive responses to the CS is also dependent on the activation of $\beta-1$ adrenoceptors within the PMd. Likewise, previous studies have shown that the PMd is critically involved in the contextual conditioning to an environment previously associated to a predator or its odor (Cezario et al, 2008; Do Monte et al, 2008). Thus, the PMd presented a marked increase of Fos expression in response to a cat- or a cat odor-associated environment, and the PMd pharmacological inactivation with muscimol blocked the expression of contextual fear conditioning to a predator-associated environment (Cezario et al, 2008; Staples et al, 2005).

As shown in Supplementary Material (Table S1), ISO microinjected into the PMd, in the odor box, was able to elicit a contextual conditioning similar to that found in response to cat odor. In this experiment, two groups of rats ( $n=5$ each) were infused with ISO40 or PBS into the PMd and positioned in the odor box, during $10 \mathrm{~min}$. After $24 \mathrm{~h}$, the subjects were re-exposed to the odor box and the defensive behavior was measured. The results showed that ISO40 into the PMd was able to elicit a contextual conditioning similar to that previously found for cat odor exposure (Do Monte et al, 2008).

We have further examined whether the effects of PMd $\beta$-adrenergic stimulation on fear conditioning would rely on a downstream sympathetic activation at peripheral $\beta$-adrenoceptors. $\beta$-Adrenergic mediation on memory processing in shock-based procedures seems to depend, at least in part, on a peripheral neuronal pathway involving $\beta$-adrenoceptors on vagal afferents terminating on brainstem noradrenergic cell groups in the nucleus of the solitary tract (McGaugh and Roozendaal, 2002). To verify the ability of ISO infusion in the PMd to induce OFC through downstream adrenergic activation at peripheral $\beta$-adrenoceptors, the rats received saline $(n=7)$ or nadolol $10 \mathrm{mg} / \mathrm{kg}$ $(n=8)$ - a $\beta$-blocker that does not cross the blood-brain barrier (Cruickshank et al, 1980) -intraperitoneally before ISO $40 \mathrm{nmol}$ conditioning. No statistical difference was detected between saline and nadolol-treated animals during the CS1 test for the \%approach time (Saline $=11 \pm 1$;
Nadolol $=11 \pm 1), \quad \%$ hide time $(S=70 \pm 3 ; \quad N=76 \pm 2)$ or \%head-out time $(\mathrm{S}=19 \pm 4 ; \mathrm{N}=16 \pm 1)$ and during the CS2 test for the \%approach time (Saline $=9 \pm 1$; Nadolol = 11 \pm 2$)$, \%hide time $(S=81 \pm 3$; $N=76 \pm 3)$, or $\%$ head-out time $(\mathrm{S}=10 \pm 1 ; \mathrm{N}=19 \pm 3)$. Therefore, the pretreatment with nadolol failed to impair the ISO-OFC acquisition, leaving out possible peripheral $\beta$-adrenergic activation in the ISO-OFC processing. Likewise, contextual conditioning to cat odor does not seem to depend on peripheral $\beta$-adrenergic mediation (Do Monte et al, 2008). Taken together, the results support the idea that both, PMd $\beta$-1 adrenergic stimulation and predator-threat-based conditioning procedures, should primarily involve psychological processing, contrasting with shock-based procedures, which involves a physically aversive stimulus likely to engage more interoceptive signaling.

The PMd is likely to exert, at least in part, its functional roles through dense and presumably glutamatergic projections to the dPAG (Canteras and Swanson, 1992; Cezario et al, 2008; Chiavegatto et al, 1998), and we have presently investigated whether this glutamatergic pathway from the PMd to the dPAG would be involved in mediating the acquisition and/or the expression of the OFC related to the PMd $\beta-1$ adrenergic stimulation. To this end, two sets of experiments were performed in rats with cannulas implanted into the PMd and the dPAG. In the first set of experiments, the NMDA receptor antagonist AP5 infused into the dPAG was able to block the OFC acquisition due to an ISO injection into the PMd. The efficacy of ISO applied into the PMd to support OFC was observed in subjects receiving either PBS inside or AP5 outside the $\mathrm{APAG}$ (in the superior colliculus). A second set of experiments was performed to verify the role of the $\mathrm{dPAG}$ glutamatergic blockade during the OFC expression. In the ISO-odor paired group, AP5 applied within the dPAG 10 min before amyl acetate odor exposure was able to partially reduce some of the behavior scored, such as the hidden time and the head-out time during the CS1 test, but failed to alter significantly the approach time. Moreover, in this experimental set, we were able to observe that the dPAG blockade impaired the second-order conditioning expression during the CS2 test, since the data from ISO/AP5 group were similar to that obtained during the familiarization session. Therefore, the dPAG seems to be involved in the acquisition of both OFC and contextual second-order conditioning, as well as in the expression of the OFC.

Recent findings have shown that pharmacological inactivation of the PAG with muscimol attenuated US-evoked responses in the amygdala and impaired acquisition of fear conditioning (Johansen et al, 2010). In line with this view, preliminary data from our laboratory have shown that pharmacological blockade of the dPAG with muscimol was also able to block the acquisition of contextual fear conditioning to an environment previously visited by a predator (Cezario et al, 2008). Considering the similarities pointed so far between PMd $\beta$-1 adrenergic stimulation and predator-threat-based conditioning procedures, it is reasonable to speculate that both procedures should utilize similar pathways to process fear conditioning. Recent studies from our laboratory have shown that NMDA lesions of the main thalamic targets of the medial hypothalamic defensive circuit (ie, the nucleus reuniens and the ventral part of 
the anteromedial nucleus) could yield a complete loss of contextual conditioned anti-predatory defensive responses, without interfering with the unconditioned responses during cat exposure (Carvalho-Netto et al, 2010). Accordingly, the influence of these thalamic targets on the contextual conditioning should involve a pathway formed by the agranular retrosplenial and postrhinal areas shown to be involved in contextual fear conditioning in studies pairing context and foot shock, likely to be mediated through the postrhinal area projections to the hippocampal formation and the lateral amygdalar nucleus (Bucci et al, 2000; Burwell and Amaral, 1998; Burwell et al, 2004; Keene and Bucci, 2008a,b). Importantly, the dPAG has strong access to elements of the medial hypothalamic system, and hence, may influence their main thalamic targets, as well. In support to this view, electrical or chemical stimulation of the dPAG has been shown to upregulate Fos expression in the PMd (Vianna et al, 2003). At this point, it seems reasonable to suggest that the dPAG's role on the acquisition of fear conditioning should probably be mediated through this thalamic path, but further experimental evidence is obviously needed to prove this hypothesis.

As previously pointed out, the $\mathrm{dPAG}$ also seems to be involved in the expression of the OFC. In line with this view, previous studies have shown that the dPAG upregulates Fos expression in response to a predator-associated environment (Cezario et al, 2008); in addition, the blockade of the expression of contextual fear conditioning to a predatorassociated environment by the PMd pharmacological inactivation with muscimol has been shown to be associated with a drastic decrease in Fos levels in the dPAG, a result compatible with a putative PAG role in the expression of predator-associated contextual conditioning (Cezario et al, 2008).

The data presented in this study highlighted the usefulness of the OFC model in rodents to unravel brain mechanisms underlying the mediation of responses to stimuli of aversive nature. A comparison among three studies, depicted as Supplementary Material (Table S2), demonstrated the similarities in the behavioral performance of rats submitted to three different US of aversive nature: cat odor (Do Monte et al, 2008), electrical footshock (Kroon and Carobrez, 2009), and ISO-40 injection into the PMd (data from the present study). Fear conditioning has always been a starting point to model PTSD, and the OFC protocol includes some of the PTSD model key aspects such as: (1) exposure to a traumatic event, (2) traumatic event reexperienced in response to internal or external cues, and (3) persistent avoidance of stimuli associated with the trauma. The sensitivity of the OFC protocol to anxiety-related drugs and the ability to maximize, in laboratory, several of the PTSD symptoms, suggest the OFC as a relevant animal model of anxiety, especially in cases where a fearful US is often internal, and not an environmental stimulus.

In conclusion, the evidence that the electrical or chemical stimulation of subcortical neural structures are able to elicit motivated driven behavioral responses lies on early operant behavioral tasks (Cazala, 1979; Delgado et al, 1954; Schenberg and Graeff, 1978), and on the ability to support associative learning in a Pavlovian fear conditioning paradigm (Di Scala et al, 1987). We have presently shown that $\beta-1$ adrenoceptor activation within the PMd serves as a
US supporting the acquisition of the OFC. Of particular relevance, $\mathrm{PMd} \beta-1$ adrenergic stimulation is a model capable to mimic predatory threat-induced internal state changes, and works as a US able to mobilize the same systems involved in the acquisition and expression of predator-related contextual conditioning. Furthermore, in this model, based on the anti-predatory defensive systems, we have also been able to show that the activation of the dPAG seems critical for the acquisition and expression of fear conditioning.

\section{ACKNOWLEDGEMENTS}

This work was supported by CAPES, FAPESP, and CNPq from which EP received doctoral fellowship and NSC and APC a research fellowship.

\section{DISCLOSURE}

We have no commercial associations that impact on this work. The funding for this study was provided by Brazilian public agencies CAPES, CNPq, and FAPESP; they had no further role in the study design; in the collection, analysis, and interpretation of the data; in the writing of the report; and in the decision to submit the paper for publication.

\section{AUTHOR CONTRIBUTIONS}

EP, NSC, and APC designed the research; EP performed the research as part of her $\mathrm{PhD}$ thesis; EP, NSC, and APC analyzed the data and wrote the paper.

\section{REFERENCES}

Barnett SA (1964). Pavlov Today. Dev Med Child Neurol 6: 270-276.

Blanchard DC, Li CI, Hubbard D, Markham CM, Yang M, Takahashi LK et al (2003). Dorsal premammillary nucleus differentially modulates defensive behaviors induced by different threat stimuli in rats. Neurosci Lett 345: 145-148.

Brennan PA, Keverne EB (1997). Neural mechanisms of mammalian olfactory learning. Prog Neurobiol 51: 457-481.

Bucci DJ, Phillips RG, Burwell RD (2000). Contributions of postrhinal and perirhinal cortex to contextual information processing. Behav Neurosci 114: 882-894.

Burwell RD, Amaral DG (1998). Cortical afferents of the perirhinal, postrhinal, and entorhinal cortices of the rat. J Comp Neurol 398: 179-205.

Burwell RD, Saddoris MP, Bucci DJ, Wiig KA (2004). Corticohippocampal contributions to spatial and contextual learning. J Neurosci 24: 3826-3836.

Bustos SG, Maldonado H, Molina VA (2009). Disruptive effect of midazolam on fear memory reconsolidation: decisive influence of reactivation time span and memory age. Neuropsychopharmacology 34: 446-457.

Campeau S, Miserendino MJ, Davis M (1992). Intra-amygdala infusion of the N-methyl-D-aspartate receptor antagonist AP5 blocks acquisition but not expression of fear-potentiated startle to an auditory conditioned stimulus. Behav Neurosci 106: $569-574$.

Canteras NS (2002). The medial hypothalamic defensive system: hodological organization and functional implications. Pharmacol Biochem Behav 71: 481-491. 
Canteras NS, Chiavegatto S, Ribeiro do Valle LE, Swanson LW (1997). Severe reduction of rat defensive behavior to a predator by discrete hypothalamic chemical lesions. Brain Res Bull 44: 297-305.

Canteras NS, Goto M (1999). Fos-like immunoreactivity in the periaqueductal gray of rats exposed to a natural predator. Neuroreport 10: 413-418.

Canteras NS, Kroon JA, Do-Monte FH, Pavesi E, Carobrez AP (2008). Sensing danger through the olfactory system: the role of the hypothalamic dorsal premammillary nucleus. Neurosci Biobehav Rev 32: 1228-1235.

Canteras NS, Swanson LW (1992). The dorsal premammillary nucleus: an unusual component of the mammillary body. Proc Natl Acad Sci USA 89: 10089-10093.

Carvalho-Netto EF, Martinez RC, Baldo MV, Canteras NS (2010). Evidence for the thalamic targets of the medial hypothalamic defensive system mediating emotional memory to predatory threats. Neurobiol Learn Mem 93: 479-486.

Cavalli J, Bertoglio LJ, Carobrez AP (2009). Pentylenetetrazole as an unconditioned stimulus for olfactory and contextual fear conditioning in rats. Neurobiol Learn Mem 92: 512-518.

Cazala (1979). Rewarding and aversive properties of electrical stimulation in the dorsal and ventral regions of the lateral hypothalamus in the mouse. Behav Neural Biol 25: 166-175.

Cezario AF, Ribeiro-Barbosa ER, Baldo MV, Canteras NS (2008). Hypothalamic sites responding to predator threats-the role of the dorsal premammillary nucleus in unconditioned and conditioned antipredatory defensive behavior. Eur J Neurosci 28: $1003-1015$.

Chiavegatto S, Scavone C, Canteras NS (1998). Nitric oxide synthase activity in the dorsal periaqueductal gray of rats expressing innate fear responses. Neuroreport 9: 571-576.

Cruickshank JM, Neil-Dwyer G, Cameron MM, McAinsh J (1980). beta-Adrenoreceptor-blocking agents and the blood-brain barrier. Clin Sci (Lond) 59(Suppl 6): 453s-455s.

Davis M (1989). Neural systems involved in fear-potentiated startle. Ann NY Acad Sci 563: 165-183.

Delgado JM, Roberts WW, Miller NE (1954). Learning motivated by electrical stimulation of the brain. Am J Physiol 179: 587-593.

Delgado MR, Nearing KI, Ledoux JE, Phelps EA (2008). Neural circuitry underlying the regulation of conditioned fear and its relation to extinction. Neuron 59: 829-838.

Di Scala G, Mana MJ, Jacobs WJ, Phillips AG (1987). Evidence of Pavlovian conditioned fear following electrical stimulation of the periaqueductal grey in the rat. Physiol Behav 40: 55-63.

Di Scala G, Schmitt P, Karli P (1984). Flight induced by infusion of bicuculline methiodide into periventricular structures. Brain Res 309: 199-208.

Do Monte FH, Canteras NS, Fernandes D, Assreuy J, Carobrez AP (2008). New perspectives on beta-adrenergic mediation of innate and learned fear responses to predator odor. J Neurosci 28: 13296-13302.

Johansen JP, Tarpley JW, LeDoux JE, Blair HT (2010). Neural substrates for expectation-modulated fear learning in the amygdala and periaqueductal gray. Nat Neurosci 13: 979-986.

Keene CS, Bucci DJ (2008a). Contributions of the retrosplenial and posterior parietal cortices to cue-specific and contextual fear conditioning. Behav Neurosci 122: 89-97.

Keene CS, Bucci DJ (2008b). Neurotoxic lesions of retrosplenial cortex disrupt signaled and unsignaled contextual fear conditioning. Behav Neurosci 122: 1070-1077.

Kilpatrick L, Cahill L (2003). Modulation of memory consolidation for olfactory learning by reversible inactivation of the basolateral amygdala. Behav Neurosci 117: 184-188.

Kincheski GC, Carobrez AP (2010). The dorsal periaqueductal gray modulates the increased fear-like behavior exhibited by experienced rats in the elevated plus-maze. Behav Brain Res 206: $120-126$.

Kroon JA, Carobrez AP (2009). Olfactory fear conditioning paradigm in rats: effects of midazolam, propranolol or scopolamine. Neurobiol Learn Mem 91: 32-40.

Lal H, Emmett-Oglesby MW (1983). Behavioral analogues of anxiety. Animal models. Neuropharmacology 22: 1423-1441.

Martinez RC, Carvalho-Netto EF, Ribeiro-Barbosa ER, Baldo MV, Canteras NS (2010). Amygdalar roles during exposure to a live predator and to a predator-associated context. Neuroscience in press (originally published online 16 October 2010, at http:// dx.doi.org/doi:10.1016/J.neuroscience.2010.10.33.

McGaugh JL, Roozendaal B (2002). Role of adrenal stress hormones in forming lasting memories in the brain. Curr Opin Neurobiol 12: 205-210.

Motta SC, Goto M, Gouveia FV, Baldo MV, Canteras NS, Swanson LW (2009). Dissecting the brain's fear system reveals the hypothalamus is critical for responding in subordinate conspecific intruders. Proc Natl Acad Sci USA 106: 4870-4875.

Nader K, Einarsson EO (2010). Memory reconsolidation: an update. Ann NY Acad Sci 1191: 27-41.

Otto T, Cousens G, Herzog C (2000). Behavioral and neuropsychological foundations of olfactory fear conditioning. Behav Brain Res 110: 119-128.

Otto T, Cousens G, Rajewski K (1997). Odor-guided fear conditioning in rats: 1 . Acquisition, retention, and latent inhibition. Behav Neurosci 111: 1257-1264.

Parker LA (2006). The role of nausea in taste avoidance learning in rats and shrews. Auton Neurosci 125: 34-41.

Paschall GY, Davis M (2002a). Olfactory-mediated fear-potentiated startle. Behav Neurosci 116: 4-12.

Paschall GY, Davis M (2002b). Second-order olfactory-mediated fear-potentiated startle. Learn Mem 9: 395-401.

Paxinos G, Watson C (1998). The Rat Brain in Stereotaxic Coordinates, 4th edn. Academic Press: San Diego.

Pentkowski NS, Blanchard DC, Lever C, Litvin Y, Blanchard RJ (2006). Effects of lesions to the dorsal and ventral hippocampus on defensive behaviors in rats. Eur J Neurosci 23: 2185-2196.

Qu LL, Guo NN, Li BM (2008). Beta1- and beta2-adrenoceptors in basolateral nucleus of amygdala and their roles in consolidation of fear memory in rats. Hippocampus 18: 1131-1139.

Restrepo D, Arellano J, Oliva AM, Schaefer ML, Lin W (2004). Emerging views on the distinct but related roles of the main and accessory olfactory systems in responsiveness to chemosensory signals in mice. Horm Behav 46: 247-256.

Richardson R, Vishney A, Lee J (1999). Conditioned odor potentiation of startle in rats. Behav Neurosci 113: 787-794.

Sam M, Vora S, Malnic B, Ma W, Novotny MV, Buck LB (2001). Neuropharmacology. Odorants may arouse instinctive behaviours. Nature 412: 142.

Schafe GE, Doyere V, LeDoux JE (2005). Tracking the fear engram: the lateral amygdala is an essential locus of fear memory storage. J Neurosci 25: 10010-10014.

Schafe GE, Nader K, Blair HT, LeDoux JE (2001). Memory consolidation of Pavlovian fear conditioning: a cellular and molecular perspective. Trends Neurosci 24: 540-546.

Schenberg LC, Graeff FG (1978). Role of the periaqueductal gray substance in the antianxiety action of benzodiazepines. Pharmacol Biochem Behav 9: 287-295.

Staples LG, Hunt GE, Cornish JL, McGregor IS (2005). Neural activation during cat odor-induced conditioned fear and 'trial 2 ' fear in rats. Neurosci Biobehav Rev 29: 1265-1277.

Vermetten E, Schmahl C, Southwick SM, Bremner JD (2007). Positron tomographic emission study of olfactory induced emotional recall in veterans with and without combatrelated posttraumatic stress disorder. Psychopharmacol Bull 40: 8-30. 
Vianna DM, Borelli KG, Ferreira-Netto C, Macedo CE, Brandão ML (2003). Fos-like immunoreactive neurons following electrical stimulation of the dorsal periaqueductal gray at freezing and escape thresholds. Brain Res Bull 62: 179-189.

Watanabe T, Nakagawa $\mathrm{T}$, Yamamoto $\mathrm{R}$, Maeda A, Minami M, Satoh M (2003). Involvement of noradrenergic system within the central nucleus of the amygdala in naloxone-precipitated morphine withdrawal-induced conditioned place aversion in rats. Psychopharmacology (Berl) 170: 80-88.
Wood SC, Fay J, Sage JR, Anagnostaras SG (2007). Cocaine and Pavlovian fear conditioning: dose-effect analysis. Behav Brain Res 176: 244-250.

Yap CS, Richardson R (2007). The ontogeny of fear-potentiated startle: effects of earlier-acquired fear memories. Behav Neurosci 121: 1053-1062.

Yardley CP, Hilton SM (1986). The hypothalamic and brainstem areas from which the cardiovascular and behavioural components of the defence reaction are elicited in the rat. J Auton Nerv Syst 15: 227-244.

Supplementary Information accompanies the paper on the Neuropsychopharmacology website (http://www.nature.com/npp) 